\title{
Erratum to: Bank vulnerability and avulsion modeling of the Bhagirathi-Hugli river between Ajay and Jalangi confluences in lower Ganga Plain, India
}

\author{
Raghunath Pal $^{1} \cdot$ Sumantra Sarathi Biswas $^{1} \cdot$ Malay Kumar Pramanik ${ }^{2}$. \\ Biswajit Mondal $^{1}$
}

Published online: 3 February 2017

(C) Springer International Publishing Switzerland 2017

Erratum to: Model. Earth Syst. Environ. (2016)

\section{2:65}

DOI 10.1007/s40808-016-0125-7

For this paper the figure captions unfortunately got mixedup. The correct captions are as follows:

Fig. 1 Location of the study area. R1 and R2 represents the reach 1 and reach 2 respectively which are most avulsive in the study section. M1 to M10 indicate the meander loops

Fig. 2 Cross-profiles across the studied reaches. P1, P2, P3, P4 represent the floodplain surface morphology. Arrows indicate the present channel position

Fig. 3 Temporal changes of the meander amplitude of two reaches from 1955 to 2011. M1 and M9 has experienced with reduction of amplitude for the cut off development

We sincerely apologize for any inconvenience caused.

The online version of the original article can be found under doi:10.1007/s40808-016-0125-7.

Raghunath Pal

raghunath.geo17@gmail.com

1 Centre for the Study of Regional Development, Jawaharlal

Nehru University, New Delhi 110067, India

2 Centre for International Politics, Organization and Disarmament, Jawaharlal Nehru University, New Delhi 110067, India 